\title{
Rencana Pengendalian Banjir di Saluran Sekunder Rungkut Barata dan Rungkut Menanggal Kota Surabaya
}

\author{
Ivanda Kurnianto, S. Kamilia Aziz \\ Departemen Teknik Infrastruktur Sipil Fakultas Vokasi ITS \\ Email: Ivandakurnianto@gmail.com
}

\begin{abstract}
Flood inundations frequently occur on the secondary channels of Rungkut Barata and Rungkut Menanggal, which includes sub-drainage system of Perbatasan channel, especially during mediumintensity and high-intensity rain. The inundations typically take place approximately 2 hours with a depth of $10 \mathrm{~cm}$ to $30 \mathrm{~cm}$, and they affect residential areas as well as main roads. The problem is allegedly caused by backwater from Perbatasan's primary channel. Rational method was employed to calculate discharge plan, with discharge $Q 5$ and $Q_{2}$ for secondary channel and tertiary channel respectively. Meanwhile, flood discharge on the primary channel was calculated using Nakayasu synthetic unit hydrograph. Furthermore, direct step method was employed to calculate backwater. The HEC-RAS results indicated that floods almost hit all segments on Rungkut Barata and Rungkut Menanggal channels. There was also backwater from Perbatasan's primary channel as far as $291.78 \mathrm{~m}$ on the downstream of Rungkut Barata's secondary channel. Flood controlling through channel normalization could be implemented to solve the problem, with 1.5 meter to 2 meter of levee height and width adjusting field condition by equalizing channel slope to 0.0004. In addition to channel normalization, flood controlling could be performed using 2 water pumps with each capacity of 0.5 $\mathrm{m}^{3} / \mathrm{s}$ and equiped with mud pump.
\end{abstract}

Keywords: Flood, Rungkut, Secondary Channel, Storage Capacity, Water Pump

Abstrak

Saluran Sekunder Rungkut Barata dan Rungkut Menanggal Kota Surabaya yang termasuk Sub Sistem drainase Saluran Perbatasan, mengalami genangan air ketika terjadi hujan dengan intensitas curah hujan sedang atau tinggi. Genangan terjadi dalam jangka waktu kurang lebih 2 jam dengan kedalaman $10 \mathrm{~cm} s / \mathrm{d} 30 \mathrm{~cm}$. Genangan terjadi di permukiman penduduk sampai ke ruas-ruas jalan utama daerah tersebut. Diduga penyebab genangan terjadi akibat aliran balik dari Saluran Primer Perbatasan. Perhitungan debit rencana menggunakan metode rasional dengan debit Q5 untuk saluran sekunder, Q2 untuk saluran tersier. Sedangkan perhitungan debit banjir pada saluran primer menggunakan hidrograf satuan sintetik Nakayasu. Adapun perhitungan aliran balik (back water) menggunakan metode tahapan langsung. Dari hasil Running menggunakan Aplikasi HEC-RAS, kapasitas saluran Rungkut Barata dan Rungkut Menanggal mengalami luapan banjir hampir di semua ruas Saluran. Pada bagian Hilir saluran Sekunder Rungkut Barata juga terjadi aliran balik dari Saluran Primer Perbatasan sejauh 291,78m. Untuk mengatasinya di lakukan Pengendalian banjir dengan Normalisasi Saluran dengan tinggi tanggul 1,5 meter sampai 2 meter dan lebar menyesuaikan kondisi lapangan dengan menyamakan kemiringan saluran menjadi 0,0004 dan melakukan pengendalian banjir mengunakan 2 Pompa air dengan kapasitas 0,5m3/det yang dilengkapi Pompa Lumpur.

Kata kunci: Banjir, Rungkut, Saluran Sekunder, Kapasitas Tampung, Pompa air 


\section{Pendahuluan}

Genangan ini diduga terjadi karena elevasi muka air banjir Saluran Primer Perbatasan lebih tinggi dari elevasi muka air banjir Saluran Sekunder Barata, perbedaaan tersebut menyebabkan terjadinya aliran backwater dari Saluran Primer ke Saluran Sekunder sehingga mengakibatkan banjir. Saluran Primer Perbatasan juga dipengaruhi oleh pasang surut air laut, jika memang benar bahwa banjir tersebut dipengaruhi oleh pasang surut air laut maka solusi yang mungkin bisa di aplikasikan menggunakan pintu air dan pompa, bila dibutuhkan juga dilakukan normalisasi saluran (Aziz, 2011).

Maksud dan tujuan Rencana pengendalian banjir di saluran Sekunder Rungkut Barata dan Rungkut Menanggal Kota Surabaya adalah:

1. Dapat mengetahui debit banjir rencana di Catchment area saluran Sekunder Rungkut Barata dan Rungkut Menanggal.

2. Dapat mengetahui besar kemampuan penampang di saluran eksisting Sekunder Rungkut Barata dan Rungkut Menanggal Kota Surabaya.

3. Dapat membandingkan kemampuan Rumah Pompa dan Normalisasi atau Parapet pada saluran sebagai alternatif mengendalikan banjir di saluran Sekunder Rungkut Barata dan Rungkut Menanggal Kota Surabaya.

\section{Metodologi}

Metodologi yang digunakan dalam studi ini adalah sebagai berikut:

A. Survey Lapangan
Survey lapangan dilakukan bertujuan untuk mengetahui kondisi di lapangan Saluran Sekunder Rungkut Barata dan Rungkut Menanggal.

B. Analisis Hidrologi

Kajian hidrologi berkaitan dengan data hidrologi yang telah didapat sebelumnya. Data-data hidologi tersebut digunakan untuk merencanakan dan menentukan debit banjir rencana dengan periode ulang tertentu. Pada analisis hidrologi ini perhitungan intensitas hujan di cocokkan dengan hasil perhitungan Pola Distribusi Hujan Surabaya (Aziz, 2016).

\section{Analisis Hidrolika}

Kajian hidrolika perencanaan dimensi saluran Sekunder Rungkut Barata dan Rungkut Menanggal meliputi:

1. Analisis Perhitungan Kapasitas Saluran menggunakan Program HECRAS

2. Melakukan tinjauan apakah ada back water di pertemuan antara saluran Sekunder Rungkut Barata dengan saluran primer Perbatasan.

3. Melakukan tinjauan apakah ada back water di pertemuan antara saluran saluran primer Perbatasan dengan Laut.

D. Alternatif Pengendalian Banjir

Alternatif pengendalian banjir harus dipilih sesuai dengan kondisi di lapangan. Beberapa Alternatif pengendalian banjir yang bisa di gunakan seperti normalisasi saluran dan pembuatan rumah Pompa. Sistem drainase pada kawasan Saluran Sekunder Rungkut Barata dan Rungkut Menanggal dilihat pada gambar 1 . 
E. Rencana Anggaran Biaya.

Rencana Anggaran Biaya merupakan perkiraan biaya yang diperlukan dalam suatu pekerjaan konstruksi. Didalam menentukan Rencana Anggaran Biaya dibutuhkan perhitungan volume galian dan timbunan, volume pekerjaan dan harga satuan pekerjaan yang nantinya digunakan sebagai acuan di dalam perhitungan anggaran

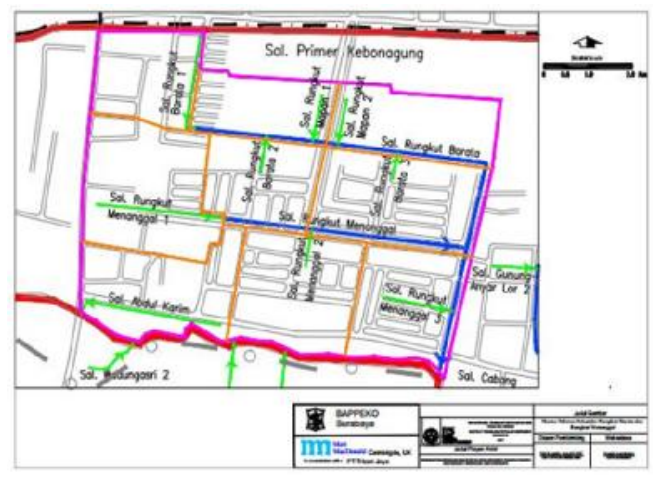

Gambar 1. Sistem drainase di Saluran Sekunder Rungkut Barata dan Rungkut Menanggal.(Dinas Pekerjaan Umum, 2000)

\section{Hasil dan Pembahasan}

A. Analisis Hidrologi

Debit banjir rencana pada umumnya direncanakan untuk pembuangan air secepatnya, agar tidak terjadi genangan air yang mengganggu. Oleh karena itu saluran-saluran drainase sebaiknya direncanakan sesuai dengan debit banjir rencana.

Pada perencanaan ini debit banjir rencana dihitung menggunakan metode Rasional, karena luas DAS $<2.5 \mathrm{~km}$.

1. Analisis Curah Hujan

Data curah hujan yang diperoleh dari Stasiun Hujan Wonorejo mulai tahun 2001 - 2015. Adapun data curah hujan harian maksimum dapat dilihat pada tabel 1.

2. Perhitungan Parameter Dasar Statistik
Sebelum dilakukan perhitungan distribusi probabilitas dari data yang tersedia, dilakukan uji parameter statistik terlebih dahulu terhadap data yang ada, sebab masing-masing distribusi (Distribusi Normal, Distribusi Gumbel dan Distribusi Log Person Type III) memiliki sifat-sifat khas, sehingga setiap data hidrologi harus diuji kesesuaiannya dengan sifat statistikanya. Pemilihan distribusi yang tidak tepat dapat menyebabkan kesalahan perkiraan yang mungkin cukup besar baik over estimate maupun under estimate yang keduanya tidak diinginkan. Hasil perhitungan awal parameter Statistik dapat dilihat pada tabel 2 .

Tabel 1. Perhitungan curah hujan maksimum stasiun Wonorejo

\begin{tabular}{ccc}
\hline Tanggal & Tahun & $\begin{array}{c}\text { Stasiun Hujan } \\
\text { Sta.Wonorejo }\end{array}$ \\
\hline 2 Maret & 2001 & 200 \\
30 Januari & 2002 & 115 \\
10 Maret & 2003 & 76 \\
5 Maret & 2004 & 85 \\
15 Desember & 2005 & 90 \\
4 Januari & 2006 & 153 \\
22 Mei & 2007 & 71 \\
20 Nopember & 2008 & 68 \\
9 Januari & 2009 & 98 \\
3 Desember & 2010 & 98 \\
9 Nopember & 2011 & 94 \\
30 Januari & 2012 & 95 \\
23-Apr & 2013 & 85 \\
6 Desember & 2014 & 100 \\
12 Februari & 2015 & 109 \\
\hline
\end{tabular}

3. Uji Kecocokan Distribusi 
Pengujian parameter yang akan disajikan dalam bagian ini adalah Uji Chi-Kuadrat dan Uji Smirnov- Kolmogorov.

Tabel 2. Hasil Perhitungan Parameter Statistik

\begin{tabular}{ccccc}
\hline Distribusi & $\begin{array}{c}\text { Parameter } \\
\text { Statistik }\end{array}$ & Syarat & Hasil & Keterangan \\
\hline \multirow{2}{*}{ Normal } & $\mathrm{Cs}$ & 0 & 2,24 & tdk diterima \\
& $\mathrm{Ck}$ & 3 & 7,84 & tdk diterima \\
\multirow{2}{*}{ Gumbel } & $\mathrm{Cs}$ & 11,396 & 2,24 & tdk diterima \\
Log & $\mathrm{Ck}$ & 54,002 & 7,81 & tdk diterima \\
Pearson & $\mathrm{Cs}$ & bebas & 1,27 & diterima \\
Type III & $\mathrm{Ck}$ & bebas & 6,30 & diterima \\
\hline
\end{tabular}

a. Uji Chi-Kuadrat

Parameter yang digunakan dalam pengambilan keputusan Chi-Kuadrat adalah $\chi^{2}$. Perhitungan parameter $\chi^{2}$ disajikan sebagai berikut :

Perhitungan jumlah sub-group

$$
\begin{aligned}
& \text { Diketahui : } \\
& \begin{aligned}
\mathrm{N} & =15 \\
\mathrm{G} & =1+1,33 \ln \mathrm{N} \\
\mathrm{G} & =1+1,33 \ln 15 \\
& =4,60 \approx 5 \text { group }
\end{aligned}
\end{aligned}
$$

\begin{tabular}{|c|c|c|c|c|c|}
\hline \multirow{2}{*}{ No } & \multirow{2}{*}{$\frac{\text { Interval }}{\text { Sub Kelompok }}$} & \multicolumn{2}{|c|}{$\begin{array}{c}\text { Jumlah } \\
\text { Data }\end{array}$} & \multirow{2}{*}{$(\mathrm{Oi}-\mathrm{Ei})^{2}$} & \multirow{2}{*}{$(\mathrm{Oi}-\mathrm{Ei})^{2} / \mathrm{Ei}$} \\
\hline & & $\begin{array}{l}\mathrm{O} \\
\mathrm{i}\end{array}$ & $\mathrm{Ei}$ & & \\
\hline 1 & $\mathrm{R} \leq 78.40$ & 3 & 3 & 0 & 0 \\
\hline 2 & $78.40 \leq X \leq 91.97$ & 3 & 3 & 0 & 0 \\
\hline 3 & $91.97 \leq X \leq 105.28$ & 5 & 3 & 4 & 1.33 \\
\hline 4 & $\begin{array}{c}105.28 \leq \mathrm{X} \leq \\
123.49\end{array}$ & 2 & 3 & 1 & 0.33 \\
\hline \multirow[t]{2}{*}{5} & $\mathrm{R} \geq 122.90$ & 2 & 3 & 1 & 0.33 \\
\hline & Jumlah & $\begin{array}{l}1 \\
5\end{array}$ & 15 & $\mathrm{X}^{2}$ & 2 \\
\hline
\end{tabular}

Hasil uji Chi-Kuadrat pada distribusi Log Pearson Type III dapat dilihat pada tabel 3.

Tabel 3. Hasil Uji Chi-Kuadrat

berdasarkan Tabel nilai kritis untuk uji Chi-Kuadrat, maka dengan $\alpha=5 \%$ diperoleh nilai $\chi^{2}=5$,991. dari perhitungan di dapat $: \chi^{2}>\chi$ ? $^{2} \rightarrow 5,991>2$. Sehingga Metode Distribusi Log Pearson Type III dapat digunakan.

\section{b. Uji-Smirnov-Kolmogorov}

Uji Smirnov- Kolmogorov dilakukan dengan maksud untuk menyaring metode distribusi yang lolos dari uji kesesuaian distribusi frekuensi dengan metode ChiKuadrat.

Dari perhitungan di atas didapatkan Dmaksimum $=-0,012$ Data pada peringkat (m) ke-2, sedangkan harga D0 $=0,34$ di dapatkan dari tabel Nilai Kritis untuk uji Smirnov-Kolmogorov, karena D max < D0 $\rightarrow-0,012<0,34$, maka uji Distribusi Log Pearson Type III dapat digunakan.

\section{Perhitungan Curah Hujan Rencana}

Hujan rencana adalah curah hujan terbesar tahunan dengan peluang tertentu yang mungkin terjadi di suatu daerah. Dari hasil uji distribusi dan uji kecocokan yang dilakukan maka perhitungan curah hujan rencana menggunakan Metode Distribusi Log Pearson Type III. Perhitungan curah hujan rencana dilakukan pada periode ulang 2, 5, dan 10 tahun. Kemudian hasil perhitungan metode Log-Pearson Tipe III akan disajikan dalam bentuk tabel seperti pada tabel 4.

Tabel 4. Perhitungan Curah Hujan Rencana

\begin{tabular}{ccccccc}
\hline $\begin{array}{c}\text { Periode } \\
\text { Ulang }\end{array}$ & Lo R & Cs & K & S & $\begin{array}{c}\text { Log } \\
\text { R }\end{array}$ & Rt \\
\hline 2 & 1.993 & 1.271 & -0.206 & 0.117 & 1.969 & 93.076 \\
5 & 1.993 & 1.271 & 0.729 & 0.117 & 2.078 & 119.731 \\
10 & 1.993 & 1.271 & 1.309 & 0.117 & 2.147 & 140.203 \\
\hline
\end{tabular}

5. Hitungan Debit Rencana dengan Metode Rasional pada Saluran Sekunder 


\section{ISSN. 1907-753X}

Rungkut Barata dan Rungkut Menanggal

Berikut ini adalah contoh perhitungan debit rencana saluran tersier Karang Tembok I :

$\mathrm{Q}=\frac{1}{3,6} \times \mathrm{C} \times \mathrm{I} \times \mathrm{A}$

$\mathrm{Q}=\frac{1}{3,6} \times 0,5 \times 29,896 \times 0,12$

$\mathrm{Q}=0,490 \mathrm{~m}^{3} / \mathrm{s}$

Dimana :

$\mathrm{Q}=$ Debit rencana $\left(\mathrm{m}^{3} / \mathrm{s}\right)$

$\mathrm{C}=$ Koefisien pengaliran

I = Intensitas hujan ( $\mathrm{mm} / \mathrm{jam})$

$\mathrm{A}=$ Luas DAS/catchment area $\left(\mathrm{km}^{2}\right)$

Hasil debit rencana pada beberapa saluran tersier dan sekunder dapat dilihat pada tabel 5 dan 6 .

Tabel 5. Debit rencana 2 tahun untuk saluran tersier

\begin{tabular}{cccccccccc}
\hline \multirow{2}{*}{ Saluran Tersier } & A & \multicolumn{3}{c}{ Intensitas mm/jam } & \multicolumn{4}{c}{ Qrencana m3/det } \\
& km2 & 2tahun & 5tahun & 10tahun & & 2tahun & 5 5tahun & 10tahun \\
\hline Saluran Rungkut Barata 1 & 0.12 & 29.896 & 38.458 & 45.033 & 0.5 & 0.490 & 0.630 & 0.738 \\
Saluran Rungkut Barata 2 & 0.12 & 35.015 & 45.042 & 52.743 & 0.5 & 0.597 & 0.768 & 0.900 \\
Saluran Rungkut Barata 3 & 0.19 & 29.847 & 38.394 & 44.959 & 0.5 & 0.789 & 1.015 & 1.189 \\
Saluran Rungkut Menanggal 1 & 0.21 & 34.228 & 44.030 & 51.558 & 0.5 & 0.983 & 1.265 & 1.481 \\
Saluran Rungkut Menanggal2 & 0.17 & 30.578 & 39.335 & 46.061 & 0.5 & 0.737 & 0.948 & 1.111 \\
Saluran Rungkut Menanggal3 3 & 0.15 & 32.388 & 41.663 & 48.787 & 0.5 & 0.669 & 0.861 & 1.008 \\
Saluran Abdul Karim & 0.16 & 31.771 & 40.869 & 47.857 & 0.5 & 0.720 & 0.926 & 1.085 \\
Saluran Rungkut Mapan 1 & 0.11 & 37.952 & 48.820 & 57.167 & 0.5 & 0.578 & 0.743 & 0.870 \\
Saluran Rungkut Mapan 2 & 0.14 & 32.719 & 42.089 & 49.286 & 0.5 & 0.629 & 0.809 & 0.947 \\
\hline
\end{tabular}

Tabel 6. Debit rencana 5 tahun untuk saluran sekunder

\begin{tabular}{|c|c|c|c|c|c|c|c|c|c|c|}
\hline \multirow{2}{*}{ Saluran Sekunder } & \multirow{2}{*}{$\begin{array}{c}\text { L saluran } \\
\mathrm{m}\end{array}$} & \multirow{2}{*}{$\begin{array}{c}\mathrm{A} \\
\mathrm{km} 2 \\
\end{array}$} & \multirow{2}{*}{$\begin{array}{l}\text { tc } \\
\text { jam }\end{array}$} & \multicolumn{3}{|c|}{ Intensitas $\mathrm{mm} / \mathrm{jam}$} & \multirow[t]{2}{*}{$\mathrm{C}$} & \multicolumn{3}{|c|}{ Qrencana m3/det } \\
\hline & & & & 2tahun & 5tahun & 10tahun & & 2tahun & 5tahun & 10tahun \\
\hline Titik kontrol 1 & 475 & 0.12 & 1.12 & 29.896 & 38.458 & 45.033 & 0.5 & 0.490 & 0.630 & 0.738 \\
\hline \multirow[t]{2}{*}{ Titik kontrol 2} & 296 & 0.12 & 0.88 & & & & & & & \\
\hline & 326 & 0.23 & 1.08 & 30.614 & 39.381 & 46.114 & 0.5 & 0.998 & 1.284 & 1.504 \\
\hline \multirow[t]{2}{*}{ Titik kontrol 3} & 265 & 0.11 & 0.78 & & & & & & & \\
\hline & 206 & 0.32 & 1.17 & 29.121 & 37.461 & 43.866 & 0.5 & 1.289 & 1.659 & 1.942 \\
\hline \multirow[t]{2}{*}{ Titik kontrol 4} & 263 & 0.14 & 0.98 & 28.232 & 36.317 & 42.526 & 0.5 & 1.438 & 1.850 & 2.166 \\
\hline & 114 & 0.37 & 1.22 & & & & & & & \\
\hline \multirow[t]{2}{*}{ Titik kontrol 5} & 314 & 0.19 & 1.12 & 25.637 & 32.979 & 38.617 & 0.5 & 1.718 & 2.210 & 2.587 \\
\hline & 273 & 0.48 & 1.41 & & & & & & & \\
\hline Titik kontrol 6 & 582 & 0.21 & 0.92 & 34.228 & 44.030 & 51.558 & 0.5 & 0.983 & 1.265 & 1.481 \\
\hline \multirow[t]{2}{*}{ Titik kontrol 7} & 318 & 0.17 & 1.08 & 29.130 & 37.472 & 43.879 & 0.5 & 1.238 & 1.593 & 1.865 \\
\hline & 401 & 0.31 & 1.17 & & & & & & & \\
\hline \multirow[t]{2}{*}{ Titik kontrol 8} & 706 & 0.79 & 1.90 & 21.006 & 27.021 & 31.641 & 0.5 & 2.300 & 2.959 & 3.465 \\
\hline & 706 & 0.79 & 1.61 & & & & & & & \\
\hline \multirow[t]{2}{*}{ Titik kontorl 9} & 343 & 0.15 & 0.99 & 19.867 & 25.557 & 29.927 & 0.5 & 2.629 & 3.382 & 3.960 \\
\hline & 289 & 0.95 & 2.07 & & & & & & & \\
\hline Titik kontrol 10 & 307 & 1.21 & 2.25 & 18.812 & 24.200 & 28.337 & 0.5 & 3.162 & 4.067 & 4.762 \\
\hline
\end{tabular}

\section{B. Analisis Hidrolika}

Analisis Hidrolika dimaksudkan untuk melakukan evaluasi kapasitas tampungan saluran dengan debit banjir periode tertentu. Evaluasi lapangan adalah pengamatan langsung di lapangan yang bertujuan untuk melihat kondisi saluran secara langsung.

1. Analisis Kapasitas Tampung dengan program HEC-RAS.

Adapun tahapan dalam analisis menggunakan software HEC-RAS adalah sebagai berikut:

a. Peniruan Geometri Saluran

Berikut hasil Peniruan geometri saluran Sekunder Rungkut Barata dan Rungkut Menanggal pada gambar 2.

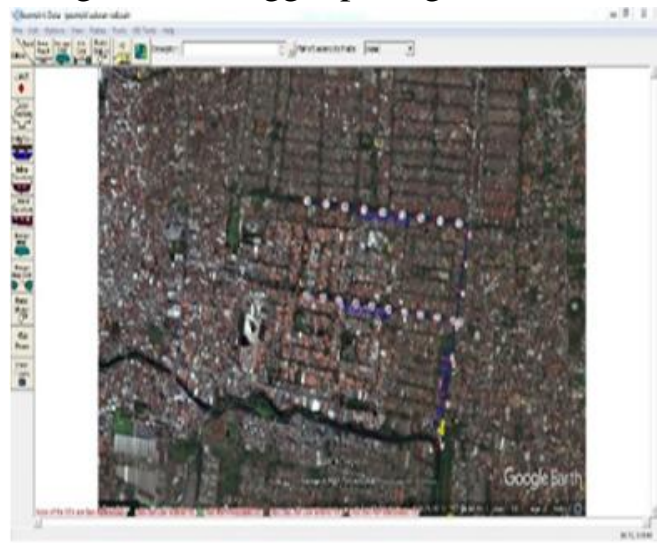

Gambar 2. Peniruan Geometri Saluran

b. Input data melintang saluran

Hasil input data saluran bisa di lihat pada gambar 3 .

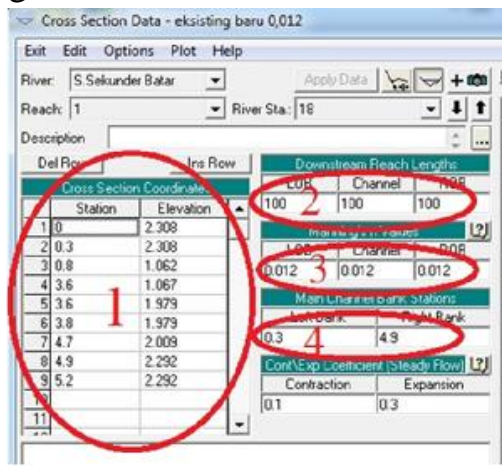

Gambar 3. Input data melintang Saluran 
Penjelasan untuk tiap nomer sebagai berikut:

1. Memasukkan koordinat titik-titik penampang melintang untuk station adalah jarak titik di ukur dari kiri dan Elevasi adalah elevasi titik.

2. Jarak antara penampang melintang, untuk jarak antara penampang melintang 18 dan 17 sejauh $100 \mathrm{~m}$.

3. Nilai koefisien kekerasan, untuk nilai koefisien kekasaran pada cross 18 sebesar 0,012 karenan saluran terbuat dari pasangan batu kali.

4. Main Channel Bank Stations, karena tampang merupakan tampang tunggal, maka seluruh tampang merupakan main channel, dengan batas kiri 0,3 dan batas kanan 4,9.

c. Simulasi aliran unsteady flow

Untuk penginputan data, flow Hydrograph terlihat seperti gambar 4 .

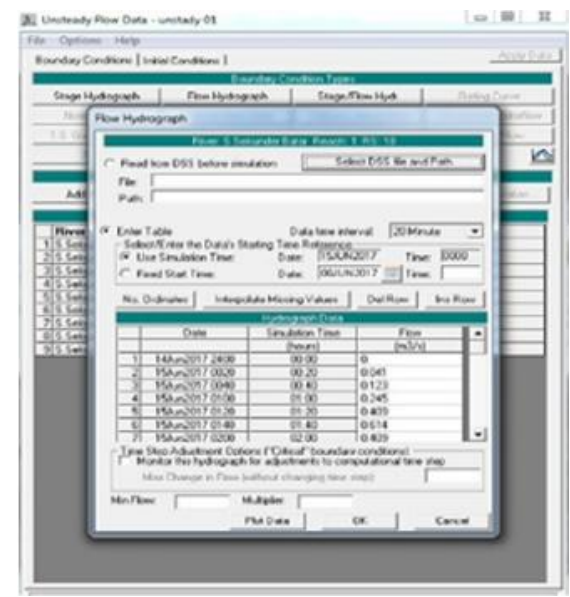

Gambar 4. Tampilan input data Flow Hydrograph

Sedangkan untuk menginput stage Hydrograph terlihat seperti gambar 5. Dari hasil Simulasi Aliran Unsteady Flow pada saluran Sekunder Rungkut Barata dan Rungkut Menanggal di dapatkan luapan antara $10 \mathrm{~cm}-80 \mathrm{~cm}$ pada beberapa cross di Saluran Sekunder Rungkut Barata dan Rungkut Menanggal.

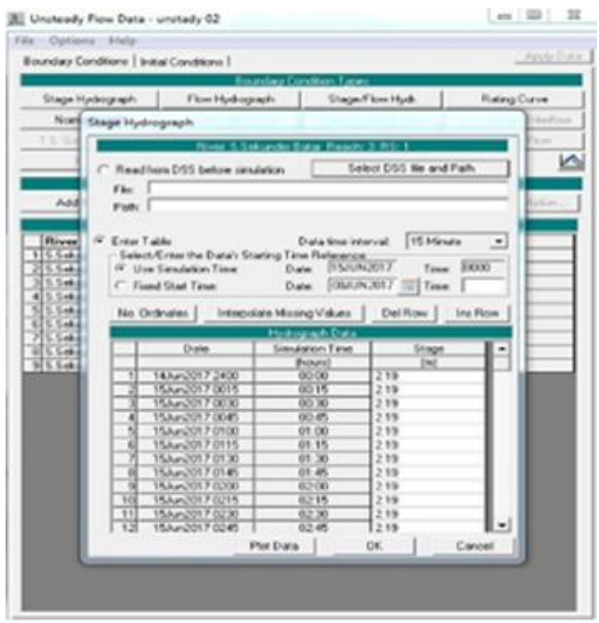

Gambar 5. Tampilan input data Stage Hydrograph

Hasil dari running dari Simulasi Aliran Unsteady Flow terlihat seperti gambar 6 dan 7.

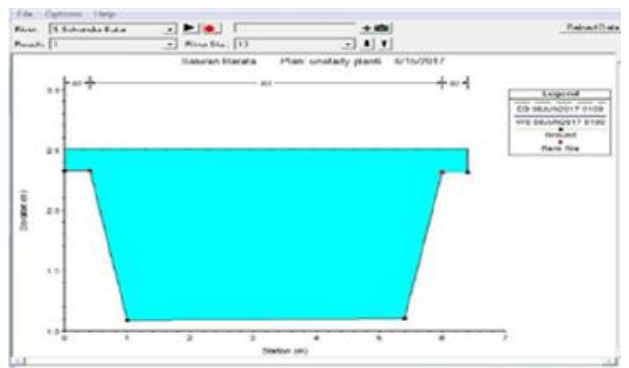

Gambar 6. Melintang Saluran

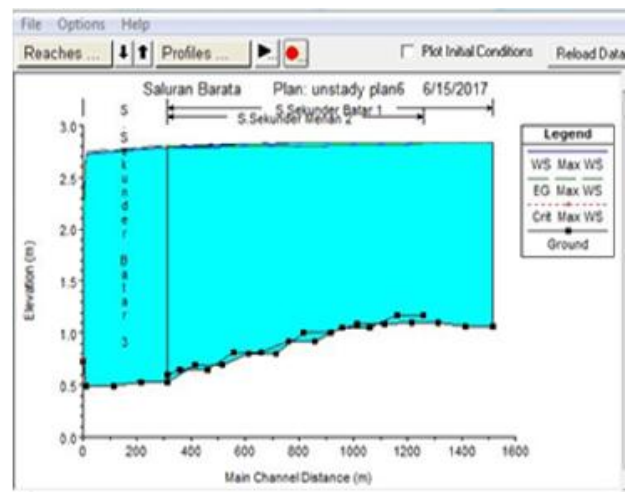

Gambar 7. Memanjang Saluran 
2. Pengaruh Aliran Balik (Back Water)

Untuk menghitung dan menentukan panjang pengaruh back water pada penampang teratur, diperlukan cara/metode Tahapan Langsung atau Direct Step Methode, sehingga didapatkan panjang aliran balik dari Saluran Sekunder Rungkut Barata menuju Saluran Primer Perbatasan yaitu sebesar 291,78 m, sedangkan panjang aliran balik dari saluran Primer menuju laut yaitu sebesar $1,13 \mathrm{~km}$. Sedangkan jarak lokasi studi Saluran Sekunder Rungkut Barata dan Rungkut Menanggal sejauh 5,2 km, dari kesimpulan perhitungan di atas didapatkan bahwa lokasi Saluran Sekunder Rungkut Barata dan Rungkut Menanggal tidak terpengaruh oleh pasang surut air laut.

\section{Alternatif Pengendalian Banjir}

Alternatif pengendalian banjir di kawasan Saluran Sekunder Rungkut Barata dan Rungkut Menanggal yang sesuai dengan kondisi lapangan adalah normalisasi dan pompa air.

1. Solusi Normalisasi dengan dilengkapi pintu air.

Perencaanan ulang untuk Saluran Sekunder Rungkut Barata dan Rungkut Menanggal:

a. Saluran yang awalnya Trapesium di buat menjadi saluran persegi dengan Tinggi $1,5 \mathrm{~m}$ sampai $2 \mathrm{~m}$ dan lebar menyesuaikan kondisi lapangan

b. Kemiringan saluran direncanakan 0,0004 .

c. Pasangan saluran mengunakan batukali yang di plester.

d. Untuk nilai koefisien kekasaran sebesar 0,012 e. Untuk hilir saluran Sekunder Rungkut Barata dan Rungkut Menanggal dipasang pintu air.

Diperoleh hasil pada gambar 8 untuk penampang melintang dan gambar 9 untuk penampang memanjang.

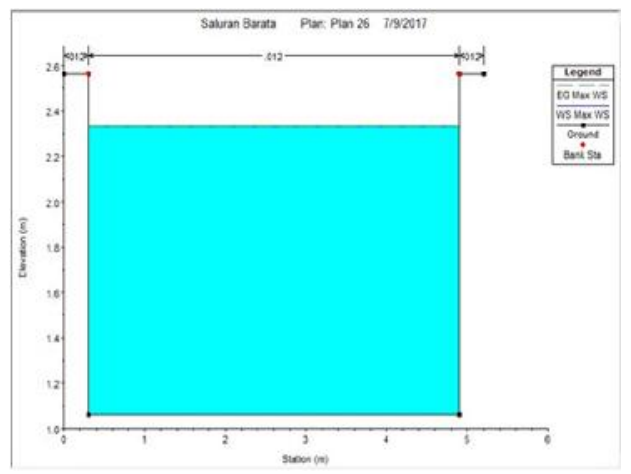

Gambar 8. Rencana Melintang Saluran Sekunder Rungkut Barata

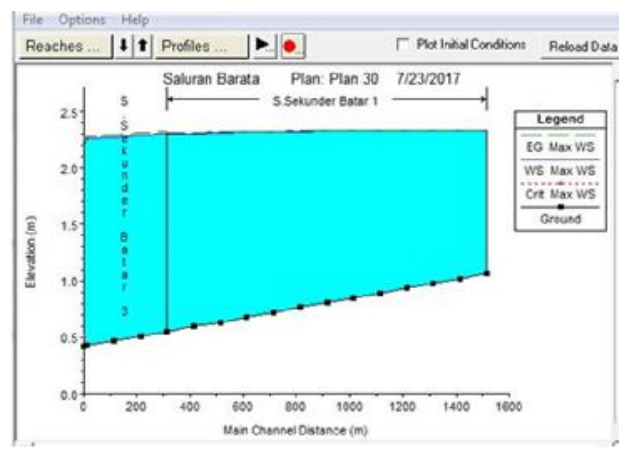

Gambar 9. Rencana Memanjang Saluran Sekunder Rungkut Barata

2. Solusi dengan Pompa Air dengan Pintu Air.

Solusi rumah pompa sendiri merupakan solusi yang sering di terapkan di Kota Surabaya yang kebanyakan saluran Sekunder di Kota Surabaya memiliki permukaan air lebih rendah di bandingkan dengan saluran primernya pada saat intensitas hujan tinggi. Dari hasil perhitungan backwater di saluran sekunder Rungkut Barata didapatkan panjang 
backwater $291,78 \mathrm{~m}$, itu sebabnya solusi rumah pompa lebih efektif untuk mengendalikan banjir. Berikut Perencanaan menggunakan Pompa Air pada saluran Sekunder Rungkut Barata:

Diketahui:

1. Debit di saluran Sekunder Rungkut Barata dan Rungkut menanggal sebesar 4,067 m³/detik.

2. Direncanakan mengunakan 2 pompa dengan Kapasitas pompa 0,5 m³/detik.

3. Untuk hilir saluran Sekunder Rungkut Barata dan Rungkut Menanggal dipasang pintu air.

Grafik pola pengurangan inflow dengan dipasangnya pompa air untuk Saluran Sekunder Rungkut Barata seperti pada gambar 10.

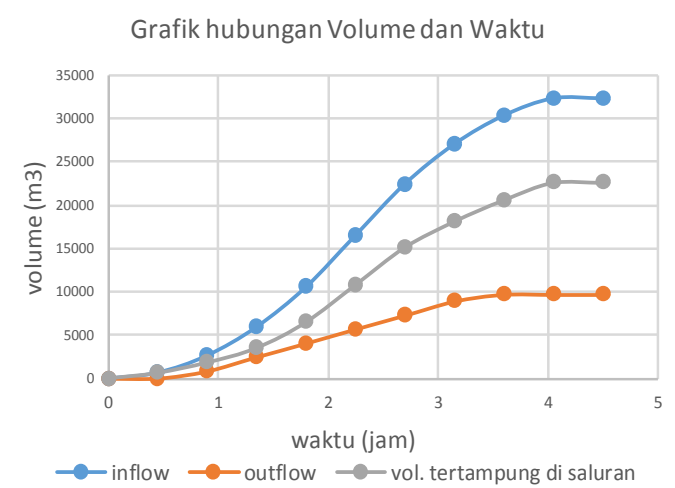

Gambar 10. Grafik Volume dan Waktu untuk Perencanaan Pompa Air.

Dari gambar 10 dapat disimpulkan bahwa dengan menggunakan 2 pompa air dengan kapasitas $0,5 \mathrm{~m}^{3} /$ detik, maka volume air yang ditampung oleh saluran sebesar $22.563 \mathrm{~m}^{3}$, sedangkan hasil perhitungan volume Saluran Sekunder Rungkut Barata dan Rungkut Menanggal, kapasitas volume sebesar $25.596 \mathrm{~m}^{3}$. Sehingga saluran masih mampu mengalirkan debit banjir rencana. Selain pompa banjir, juga dilengkapi dengan pompa lumpur dengan kapasitas $0,25 \mathrm{~m}^{3} /$ detik.

\section{Simpulan}

Dari hasil analisis dapat disimpulkan bahwa:

1. Penyebab dari banjir di kawasan Saluran Sekunder Rungkut Barata dan Rungkut Menanggal adalah dimensi Saluran Sekunder Rungkut Barata dan Rungkut Menanggal yang tidak mampu menampung debit banjir dan adanya pengaruh backwater dari saluran Primer Perbatasan sejauh 291,78 m.

2. Solusi pengendalian banjir yang pertama ada normalisasi pada saluran dengan tinggi Saluran 1,5 m dan lebar menyesuaikan kondisi lapangan. Saluran sendiri di desain berbentuk persegi dan di rencanakan dengan kemiringan saluran 0,0004. Desain saluran menggunakan pasangan batu kali yang dilengkapi dengan pintu air di hilir saluran.

3. Solusi pengendalian banjir yang kedua yaitu mengunakan Pompa air. Pompa air di lengkapi dengan Rumah jaga, kolam penampung, pintu air, dan saringan sampah. Pompa yang di gunakan ada 2 pompa banjir dengan kapasitas $1 \mathrm{~m}^{3} /$ det dan $0,5 \mathrm{~m}^{3} /$ det dan juga di lengkapi dengan pompa lumpur dengan kapasitas $0,25 \mathrm{~m}^{3} /$ det.

\section{Daftar Pustaka}

Aziz, S. Kamilia, dan Ismail Sa'ud. 2016. Pola Disribusi Hujan Surabaya. Jurnal Aplikasi Teknik Sipil. vol. 14, hal 9-15. 


\section{ISSN.1907-753X}

Aziz, S. Kamilia, 2011.Pola Pengendalian

Banjir pada Bagian Hilir Saluran

Primer Wonorejo Surabaya. Jurnal

Aplikasi Teknik Sipil. vol. 9, hal 33-40.

Badan Standarisasi Nasional. 2016. Tata cara perhitungan debit banjir rencana. SNI 2415.

Dinas Pekerjaan Umum Bina Marga dan

Pematusan. 2000. SDMP.

Surabaya: Pemerintah Kota

Surabaya.

Suripin. 2004. Sistem Drainase Perkotaan

yang Berkelanjutan. Yogyakarta:

ANDI Offset.

Soewarno. 1995. Hidrologi. Bandung:

NOVA.

Triatmodjo, B., 2010. Hidrologi Terapan.

Yogyakarta: Gadjah Mada

University Press.

Wesli. 2008. Drainase Perkotaan.

Yogyakarta: Graha Ilmu. 
